\title{
ANALYSES OF COLLABORATIVE INNOVATION ACTIVITIES THROUGHOUT THE STAGES OF INNOVATION PROCESS
}

\author{
Sercan Ozcan ${ }^{1} \quad$ Nazrul Islam ${ }^{2}$ \\ ${ }^{1}$ Bahcesehir University, Faculty of Engineering and Natural Sciences, Istanbul, Turkey, \\ sercan.ozcan@eng.bahcesehir.edu.tr \\ ${ }^{2}$ University of Exeter, The Business School, Exeter, UK, \\ n.islam@exeter.ac.uk
}

\begin{abstract}
:
The aim of this study is to analyse collaborative innovation activities based on the different stages of innovation process. There are various studies that examine determinants of collaborative innovation with regards to involvement of different types of actors, national differences and technological factors. This study examines collaborations focusing on three main stages that are input, transformation and output. It adapts these three stages throughout case studies that are within nanotechnology field to identify key issues related to the innovation process.
\end{abstract}

For this study, the key nanotechnology experts who have knowledge and involvement in collaborative innovation were interviewed in the in-depth interviews to capture the required data. The interview data for this research was collected from the UK, the US, China and Germany from 42 experts within academia, industry and intermediaries. Each expert gave an example of collaborative innovation that they involved in within the nanotechnology field. After the collection of the interview data, it is analysed by using the axial hierarchical coding procedure by embedding the findings into the innovation processes.

Finally, this study proposes a framework to differentiate various stages of collaborative innovations between academia and industry. Evidently, industrial or academic players do become involved at different stages of an innovation system. The collaborations between them do not start from the beginning of an innovation process, when the idea is generated though sometimes collaboration occurs for intellectual property related issues. Based upon findings, the cases and their determinants are explained according to the input, pretransformation, transformation, post-transformation and output stages. The results show that there is a great variance between the key success factors of different stages of collaborations. Additionally, national differences were identified with regards to the frequency of actors' involvement within the various stages of collaborative process. 


\section{INTRODUCTION}

There are various studies that look at how R\&D collaboration benefits the entire innovation process. Generally, it can be claimed that R\&D collaboration has obvious positive impacts on the innovation process considering the resource-based view but, of course, these assumptions need to be proven on a purely scientific basis when it comes to the efficiency and affectivity of end result of innovative activities.

There are different types of collaborative innovation such as: strategic alliances with the aim of innovation, R\&D consortia, intellectual property (IP) related agreements, technology-transfer activities, innovation clusters and networks. In an innovation system, collaboration networks can take different forms, for example that of an industry cluster [4]. Some of the benefits of being a part of such a collaborative innovation can be: sharing information and expertise such as buyer/supplier externalities; making use of common resources such as technological tools; and providing mutual support when various business opportunities/challenges arise.

Looking at the general view and without an in-depth analysis of inter-organisational collaborations, many individuals may assume that collaborative innovation is supportive considering the goals of firms, but Huxham and Macdonald [6] have stated that, "there is a fine balance to be struck between gaining the benefits of collaborating and making the situation worse" (p. 50). The advantages and disadvantages of collaboration need to be balanced as Anderson and Jap [1] show that there is a high failure rate of collaborations

Studies in this field show that collaborative innovation is beneficial for capacity and longevity of R\&D activities but it needs to be managed well to enhance benefits of it. To establish a better atmosphere for collaborative activities, there are many studies focusing on the innovation systems and collaborations aiming to describe the processes and interactions between actors to facilitate the value chain from the beginning of an invention to a commercialized innovation stage [12, 14].

Compared to the existing studies, this study differs by focusing on how collaborative innovation activities alter based on different phases of innovation process. There is a 
proposed framework for the collaboration activities in relationship to the innovation process. The existing studies looks at these differences based on different regions, different types of actors or different sectors but they do not focus on the possible differences in collaborative innovation activities when those different stages of innovation are considered.

This research aims to analyse inter-organisational collaboration activities in general and specific to the nanotechnology field as the collected data specific to those nanotechnology related companies. This research proposes and adapts a framework to be used in its analyses and also in future studies. Following these frameworks, this study investigates following aim and objectives:

To analyze what kind of collaboration mechanisms exist at different stages of the innovation process:

a. What the relationship is between the innovation process and interorganisational collaboration activities;

b. How the different stages of innovation impact collaborations between organisations.

\section{LITERATURE REVIEW}

This literature review (LR) focuses on horizontal collaborations between organisations and not vertical collaborations. Moreover, it focuses on firm-level collaborations but not inventor-level collaborations. Inter organisational activities require strong and official relationships between actors, whereas individual-level efforts may consist of mere knowledge sharing between parties. Examination of the collaboration literature is related to the innovation process, and $\mathrm{R} \& \mathrm{D}$ and technology-related relationships. Interactions between organisations can occur for various reasons (i.e. market conditions or financial factors) but this study limits them to innovation-related collaborations. 
After reviewing many literatures that focus on the function of collaboration, it shows that: authors studied this field to identify benefits $[3,5,10,11]$, and to examine negative effects $[2,8]$ and risks of collaboration mechanism [7, 9]. Some of the benefits of the collaboration mechanism that are studied are related to cost reduction [5], innovation performance [5], evolutionary improvement [10], patent quality [3] and sustainability of innovation [11]. On the other side, there are some studies that point out the negative effects of collaboration, such as the risks of outsourcing [7], prolonging the research time frame [5], and possible negative effects of repeated collaboration [3] in patent qualities.

The selected categories and the purpose of these studies can be seen below in Table 1 . The selection of these categories is based on the research focus and their relevance to each other. Some of the issues related to these categories are represented based on their significance for reasons such as research trend and its stage of development. However, there are many other issues covered related to these categories and they will be dealt with in the following sub-sections.

Table 1: The summary of the systematic review of literature in collaborative innovation

\begin{tabular}{|l|l|}
\hline $\begin{array}{l}\text { Categories of } \\
\text { literature on } \\
\text { collaborative } \\
\text { innovation }\end{array}$ & $\begin{array}{l}\text { Key issues from the reviewed literature based on importance, } \\
\text { trend and development }\end{array}$ \\
\hline $\begin{array}{l}\text { Actor based } \\
\text { determinants }\end{array}$ & $\begin{array}{l}\text { To identify influences/roles of different types of actors in } \\
\text { collaborations (i.e. academia or industry and small and medium- } \\
\text { sized enterprises SMEs or large firms etc.) } \\
\text { To understand the key factors when same/different actors } \\
\text { collaborate together }\end{array}$ \\
\hline $\begin{array}{l}\text { Geographical and } \\
\text { proximity related } \\
\text { studies }\end{array}$ & $\bullet \begin{array}{l}\text { To understand factors related to geographical location such as } \\
\text { different countries }\end{array}$ \\
\hline $\begin{array}{l}\text { Innovation or } \\
\text { technology based } \\
\text { issues }\end{array}$ & $\begin{array}{l}\text { To examine proximal related issues such as if two actors are } \\
\text { geographically far from/close to each other }\end{array}$ \\
\hline $\begin{array}{l}\text { To identify different determinants in collaborative innovation when } \\
\text { different innovation types (e.g. radical, incremental) and different } \\
\text { technologies are considered (e.g. telecommunications, electronics) }\end{array}$ \\
\hline $\begin{array}{l}\text { Ondividual level } \\
\text { centred analyses }\end{array}$ & $\begin{array}{l}\text { To examine the influence of different structure of organizations (e.g. } \\
\text { if the organization structure is open to collaboration or an efficient } \\
\text { structure for collaborative innovation etc.) } \\
\text { To examine individual level factors (e.g. cultural issues, personal } \\
\text { relationships etc.) }\end{array}$ \\
\hline
\end{tabular}




\begin{tabular}{|l|ll|}
\hline $\begin{array}{l}\text { Fund and policy } \\
\text { related issues }\end{array}$ & $\begin{array}{l}\text { To analyze the influence of funds and innovation policies in } \\
\text { collaboration mechanisms } \\
\text { To propose types of funds and policies that generate collaborative } \\
\text { innovations }\end{array}$ \\
\hline $\begin{array}{l}\text { Cross-sectorial and } \\
\text { interdisciplinary } \\
\text { research }\end{array}$ & $\bullet \begin{array}{l}\text { To find key determinants when there are different sectors or } \\
\text { disciplines involved in the same collaborative innovation }\end{array}$ \\
\hline $\begin{array}{l}\text { Network, cluster, } \\
\text { collaboration } \\
\text { structure }\end{array}$ & $\begin{array}{l}\text { To identify different types of network, cluster and collaboration } \\
\text { structures } \\
\text { To examine the influences of different network types in innovation } \\
\text { processes }\end{array}$ \\
\hline
\end{tabular}

After reviewing literatures in this field, it is apparent that collaborative innovation has both negative and positive outcomes depending on different factors. The different outcomes of collaboration in innovation are mainly found to be based upon special circumstances and unique determinants.

There are not many studies related to the determinants and cases of collaborative innovation with regards to the different phases of innovation process. Zeidner and Woods' [15] study is highly relevant as they were also focusing on the collaborative innovation process. This model is very comprehensive with regards to the stages of collaborative innovation but it lacks the details of organisational needs and determinants when it comes to the innovative activities. Moreover, it has very limited cases where it illustrates how collaboration related needs differ at different stages of innovations. The Process of Innovation in Alliances [16] is another relevant model for this study. In their model, alliance creativity, alliance learning, alliance knowledge stock and alliance innovation are shown in a model that is called "chain of innovation”. This study mostly focuses on the individual level factors related to the motivational, cultural and critical thinking related aspects. Also, it explains structural elements such as centralisation and absorptive capacity when it comes to alliances. However, their study does not focus on the 'big picture' rather it focuses on individual level or very structural issues.

Having reviewed relevant studies, it is assumed that innovative collaboration will differ at different stages of the innovation process for inter-organisational collaborations. It cannot be expected that related determinants and the process will be the same if the 
innovative collaboration occurs at the beginning or at the end of an innovation phase. The proposed framework in Figure 1 illustrates one of the general models of this study that are applied within the study. Accordingly, one can assume that determinants of collaboration between various actors will differ if it occurs at different stages of an innovation process. Evidently, industrial or academic players do become involved at different stages of an innovation system and the collaborations between them do not start from the beginning of an innovation process when the idea is generated, though sometimes collaboration occurs for IP related issues.

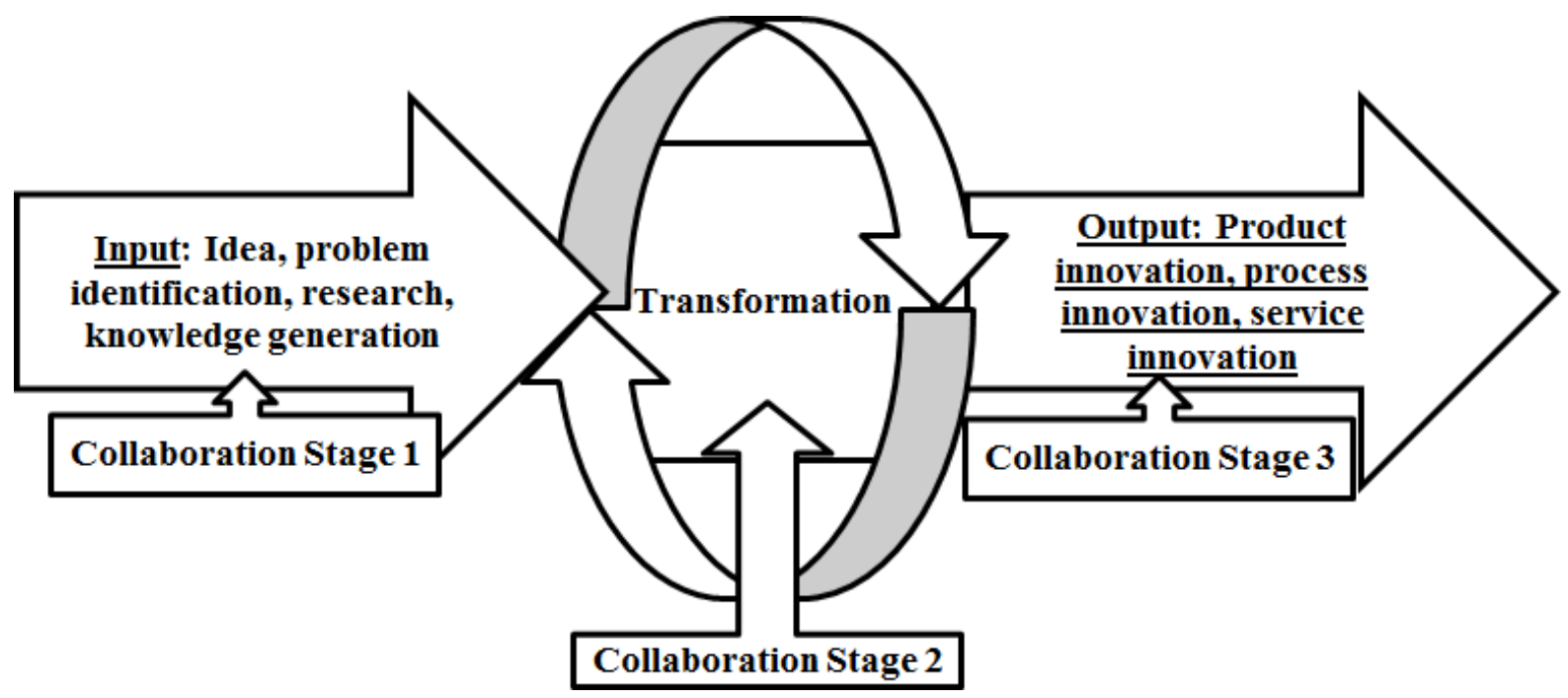

Figure 1: Proposed Framework for the Stages of Collaboration

\section{METHODOLOGY}

This study uses interview analysis to explore and analyse the relationship between innovation process and collaborative activities. The key phases of an interview method, such as interview design, data collection and analysis are explained in the following sections (please see Figure 2). 


\begin{tabular}{|l|l|}
\hline $\begin{array}{l}\text { - The design of interview questions according to the } \\
\text { literature review }\end{array}$ \\
\hline - Sample selection (purposive selection) \\
\hline $\begin{array}{l}\text { - Scheduling interviews and gathering interview data from } \\
\text { selected individuals }\end{array}$ \\
\hline - Transcription and coding the data \\
\hline - Interview data analysis with the help of Nvivo.
\end{tabular}

Figure 2: Steps of the Interview Method and Analysis

The selected interviewees are from managerial level who were involved in collaborative research activities for nanotechnology field. For this research, the interview data was collected from the UK, the US, China and Germany from 42 experts that within academia, industry and intermediary sectors. A purposive sample selection was carried out to identify individuals who were involved in collaborative R\&D activities of nanotechnology field. The selected organisations were of various sizes: large entities, SMEs and start-up level organisations.

Some of the interviewees would like to remain anonymous. However, for purposes of representation, some of the key nanotech experts who were interviewed can be listed as follows: 1) from China, Prof. Fan Shoushan, the director of Tsinghua-Foxconn Nanotechnology Research Centre; 2) from the UK, many nanotechnology related specialists were interviewed such as Prof. Jeremy Baumberg, Director of the Nanophotonics Centre at Cambridge University; 3) for Germany, key actors were interviewed from Fraunhofer such as Dr. Karl-Heinz Haas who is the Deputy spokesman of the Fraunhofer Nanotechnology Alliance and head of the nanotech institution; and 4) for the US, employees of nanotechnology oriented firms were interviewed such as the director of NanoWave. 
Many targeted and open-ended questions were asked to capture relevant information and considering the objectives of this research, groups of questions were selected covering inter-organisational collaboration activities, factors that influence collaboration mechanisms between actors and also at the end of the interview, subjects were asked to give an example of their nanotechnology related collaborative involvement where they were involved in any phases of the innovation process.

These themes are used to formulate the open-ended questions in order to capture data regarding the following matters:

- Collaboration approaches with regards to different stages of the innovation process,

- The influence of innovation phase on the inter-organisational collaboration activities,

- Successful cases and examples of R\&D collaboration processes where different actors were involved in the innovation process from the beginning to end.

After a detailed transcription of the collected data, the interview data was cleaned and formatted to be loaded into Nvivo software (the software that is designed for qualitative work with text-based research). After the transcription, cleaning and loading of the data into Nvivo were completed, the classification of the nodes was mapped onto the loaded interview data source in order to differentiate findings based upon different categories and groups. Accordingly, a classification was created based on three attributes: 1) country, 2) type of actor, and 3) size of actor.

After adding values to the interview data and classifying them, in the next step, the conceptualization, coding, and categorizing procedures were initiated. For the coding procedure a two-step procedure was used where a prior coding is applied to identify general themes and ideas. Afterwards, an interpretive coding is applied to find specific patterns in the data. To sort the codes into groups, the axial coding procedure was followed. To give an example, many fund related codes were identified as an influential issue for the collaboration mechanism. These codes are grouped into a more general 
theme that is "fund issues in collaborations". For a specific example, please see Table 2 which illustrates how the data is coded into this fund related theme.

Table 2: An illustrative list for coding of the interview data for all funding related codes

\begin{tabular}{|l|}
\hline Funding issues in collaborations \\
\hline Collaborative funding and competitors \\
\hline Firms fund contribution \\
\hline Fund allocation by academia \\
\hline Fund distribution \\
\hline Funding in fundamental vs. applied research \\
\hline Government's involvement \\
\hline Limitation of fund \\
\hline More actors, less fund share \\
\hline Different types of actors' fund allocation \\
\hline Inefficiency in collaborative innovation funds \\
\hline
\end{tabular}

After the coding and grouping according to common themes, some general issues were examined, such as summarizing the frequency of codes, identifying the most repetitive ones and differentiating them based on a previously completed classification. To write up the analysed data, a comparative design was used for different stages of innovation and also attribute that are generated. The proposed model is used to fill up the innovation process with different stages of collaborative activities.

\section{RESULTS AND FINDINGS}

Based upon interviews with nanotechnology-related companies, a number of stages were identified in their innovation processes, from idea creation or problem recognition, to the last phase of innovation. Figure 3 shows the five different stages of innovation process and what types of collaborative activities occur. In the following sections, different types of organisational needs are explained in each stage of the innovation process.

In the input phase, collaborations occur mainly internally between scientists. However, there are two current approaches that encourage organizations to collaborate at this level. The first one is collaborative fund applications, such as the FP7 program. The aim of this program is to bring various nanotechnology organizations together into the same project. Using this mechanism, it is possible to align the work of academia and industry from the 
outset, such as in the example of the production mechanism for graphene. The second common approach for early phase collaboration is brought about by direct investment from one large organization in another. This mainly occurs between industry players and academia. For example, large organizations like Samsung, Toyota, and Foxconn invest in universities to establish research facilities that work to meet industry requirements from the very first stages of their research work.

The next stage is termed pre-transformation. This stage and its related collaborations are often difficult to distinguish from the previous one, but it is one of the collaboration stages that initiates the process of conducting research. It is not truly the beginning of the research process where such activities as idea generation or problem identification are performed since many preliminary steps have already been taken. At this stage, many industrial actors approach academic actors to clarify or verify further various research ideas/problems related mainly to fundamental/basic research issues, and academic actors approach industrial actors with regard to applying research to many industry or market related needs/problems. Collaborative innovation activity at this stage occurs once firms are aware of the industrial problem or market need. In one of the interview cases, an industrial actor was aware of the market gap and the required product for it, and so they approached an academic actor to identify some physical characteristics of a nanomaterial. Accordingly, the academic actor tested the material and clarified the issues with regard to the material and so the industrial actor could further work on the production problems.

Many organisations at the pre-transformation stage approach other organisations to test and identify technical barriers or potential problems of a certain technology so that they can avoid risky investments. At the pre-transformation stage, many scientists identify the requirement for support from different parties during the early research work. Other preliminary considerations include the requirement for expertise from different fields, the requirement for different research tools, or the requirement for tests and measurements of samples by industry players. Also, due to the large investments at stake, many SMEs will want to send their samples to be tested, measured, and have characterisations of their materials completed before they finalize their research and move on the next stage. 
Academic institutions often approach industrial players at this stage to learn from them about applied research needs.

Collaborations in the transformation stage occur mainly when an organization has IP rights to a technology or can obtain the IP rights in the near future. Also, sometimes some firms do ask for academic actors' help with regard to the application of their patented technology. Accordingly, some organisations have the IP right for a technology but do not know how to exploit the technology commercially. It is often difficult to establish trust relationships in these types of situations, since the IP owner tends to protect the secrecy of the technology and often is unsure which organizations it should share its technology with to achieve the best commercial results. Also, there were various cases where collaborations started without the IP rights but these kinds of collaboration structures usually would already have started at the input and/or pre-transformation stage. This is one of the stages where there is usually a high level of involvement on the part of different types of organizations other than the main industry players. Some intermediary actors are also highly involved at this stage, such as consultants, advisors, patent authorities, and IP lawyers. There were some collaboration mechanisms found where industrial organizations collaborated with academic organizations to further improve their existing patents. Therefore, IP rights are not used only for commercialization or as a barrier for competitors, but they also allow organizations to collaborate on their existing technology to further improve or protect it. Some academic organisations stated that IP ownership is not compulsory for collaboration to take place but it makes the procedure easier. Many firms were aiming to understand how to transform their patented or nonpatented technology into an actual product, service or process.

Collaborations in the post-transformation stage fall into two broad categories: (1) where organizations transfer the technology to other parties; or (2), where they try to commercialise it themselves. Both collaboration structures require different elements from different types of actor. The collaboration method at this stage differs based on the types of actor. If it is an industrial actor, they usually would like to go commercial but in some cases they are willing to collaborate with academic organisations to develop the technology further. If the discussed actor is an institution then both paths are found to be 
the practice but the most common procedure is the technology transfer process. For example, even though the Fraunhofer Institute's main concern is to transfer their science into other organisations, they currently do follow spin-off procedures when necessary. This is an indication that many research and science oriented organisations have begun to explore the commercial path and this leads to a more productive and applied-oriented research.

For academic actors at the post-transformation stage, the common path is mainly the technology transfer process to large firms or SMEs but spin-off type firms appeared to be a frequent case, especially in the UK, Germany and the US, but it was rare in China. At the following stages, the spin-off type organisations were found to be commercially successful and to continue to collaborate with the same academic organisation from which innovation originated. Technology transfer models are the most collaborative structures of the mechanisms discussed so far. This level usually shows the highest-level involvement on the part of SMEs, as they rely on academia rather than their in-house R\&D. However, large organizations also sometimes collaborate at this level, such as in the case of Foxconn and Tsinghua University. But, these are rare cases, since significant investments are required to agree on IP rights and this was found to be one of the biggest concerns for industrial actors, since many criticised the required IP related fees. Furthermore, actors who would like to commercialise products themselves still rely on other parties for mass production. Mass production is a key issue in the nanotechnology field that needs to be addressed and this is one of the reasons why organisations collaborate at the output stage.

At the output stage, collaborations occur mainly between industrial players but there are various collaborations where both academic and industrial actors are involved in resolving industrial issues. An example of collaborations between two industrial actors is where some firms have the expertise to produce certain nano-particles and have access to the market, but they cannot fulfil the needs of industry, so they collaborate with some other industrial players that produce the required materials for them. Then, they process these materials to produce their own products and provide them to their clients. At this level, it was found that many nanotechnology industrial players are not willing to 
collaborate with each other and this was one of the significant issues that needed to be addressed in order to promote commercialisation in the nanotechnology field. But, while this is not generally a highly collaborative stage, some industrial players were found to be collaborating through strategic alliances or collaborative funded procedures such as the agreement between Oxford Advanced Surface and Sun Chemical Ltd to work on radiation curable nanotechnology coatings, with funding from the UK's innovation agency, the Technology Strategy Board. As such, SMEs often have greater motivation to pursue this type of collaboration, especially if the collaborative fund is provided as they have limited resources compared to large organisations. Since mass production is one of the main challenges in nanomaterial manufacturing, many organisations have targeted research at this stage to resolve manufacturing procedures so that they can optimise their system to capture economies of scale. 


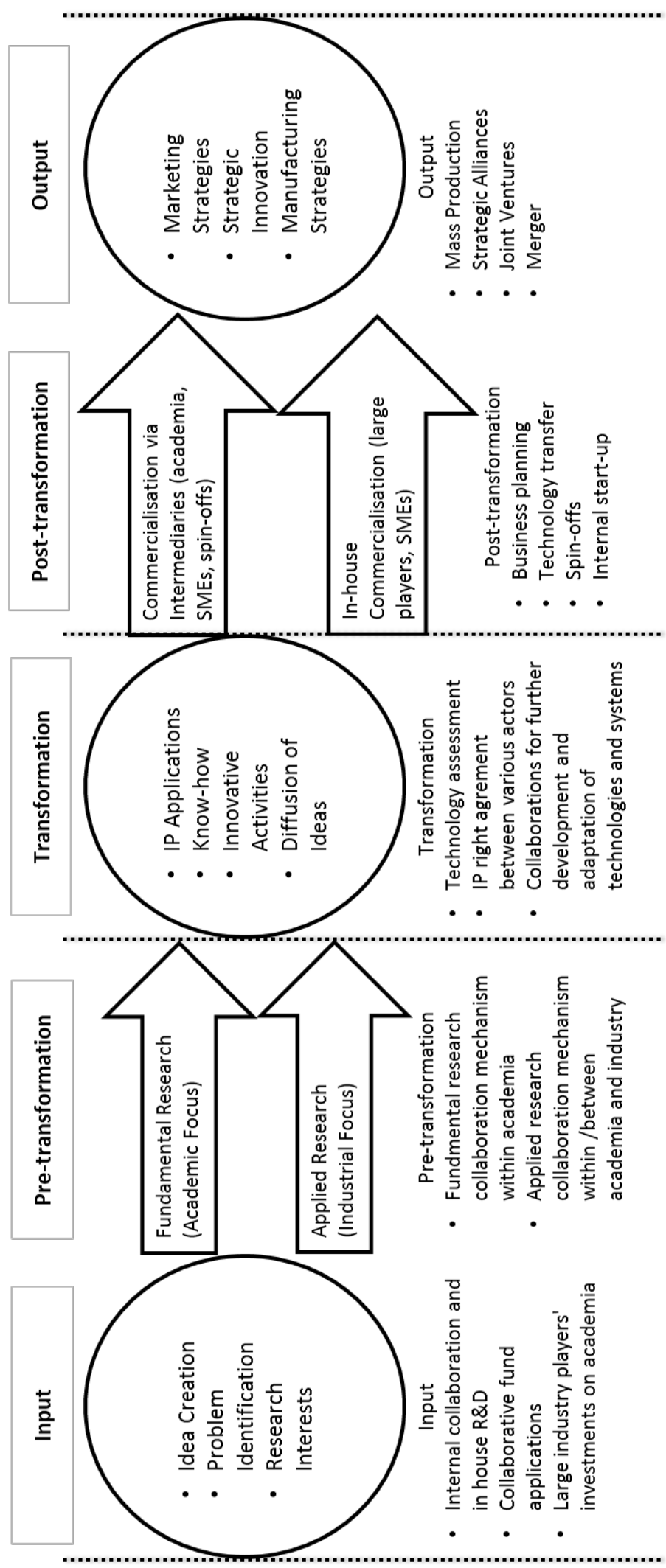

Figure 3: Inter-organisational Collaborations at Different Stages of Innovation Process 


\section{CONCLUSION}

The findings of this study have thrown light on the different functions of collaboration in different stages of the innovation process. Five different collaborative innovation phases have been described including input, pre-transformation, transformation, posttransformation and output stages.

The review of existing studies in the field showed that other scholars did not consider the possible impacts and causes of collaborations if they occurred at different stages of the innovation process. Accordingly, the proposed model aimed to test if the collaboration activities would differ in terms of type and role when the stages of innovation were considered. This research found great differences in collaborations when they are considered at different stages of the innovation process. Accordingly, this model can be generalised to examine the overall involvement of an organisation in an innovation process to identify at what stage their collaborations most frequently occur and at which points gaps need to be addressed. Also, many theoretical frameworks are available to illustrate the general processes and functions of a system. This model also allows practioners to see the general picture with regard to the differences and function of collaborations in different stages of the innovation process.

As explained earlier where the theoretical contributions are stated, this study proposed and analysed a framework related to the different phases of the inter-organisational innovation collaboration process. Accordingly, five different stages were identified and explained within the study. It must be stressed here that these stages do not indicate that all collaborations pass through these phases from beginning to end. Some collaborations begin and end at a single stage. For example sometimes a new collaboration starts at the last stage. These stages indicate the differentiating factors for collaborations in an innovation process.

In the input phase, collaborations were found to be mainly between scientists or between large industrial and academic organisations. These types of collaboration were found to be targeting exploratory research work to identify problems in the research or market. The availability of funds for academia at this stage appears to be crucial. Also some large organisations like Samsung, Toyota, and Foxconn have invested in universities to 
establish joint research facilities that work to meet industry requirements from the very first stages of their research work. The next stage was called pre-transformation. At this level the research problem and market targeted ideas are clarified to further the collaboration. For the nanotechnology field, some of the preliminary considerations at this stage were knowledge sharing such as expertise from different disciplines, the requirement for different types of research tools, or the requirement for tests and measurements of samples on the part of industry players. The third stage for collaborative innovation was the transformation stage. There were numerous reasons for organisations to become involved in these collaborations such as IP rights and the integration of technologies into products or services. The fourth stage was the point at which organisations transfer technology to other parties or where they try to commercialise it themselves. The final stage was the output stage where most of the collaborations occurred between industrial actors related to market problems.

Some practical findings of the study:

- Looking at the various stages of collaborations, new funding systems appear to be an effective way to encourage (or force) companies to work together from the initial stage of collaboration.

- In most collaboration stages, it appears that large organisations are currently the key organizations in the nanotechnology field for the commercialisation process, especially in some of the fields such as the electronics industry where high investments are required.

- Large organisations should consider establishing units/departments within universities and institutions as in the case of Foxconn-Tsinghua so that the efficiency and effectiveness of collaborations be increased and collaborations start from the input stage of the innovation process.

This model can be adapted for other research areas to examine the collaboration mechanism in a nation or in a certain sector. The stages of collaboration model could be used by any type of actor to assess the stage of innovation at which the collaboration 
occurs. This would allow practitioners to map the whole process in these types of activity. These two models are presented as theoretical contributions to the field due to their generalizability and applicability to other fields of study. 


\section{REFERENCES}

[1] E. Anderson and S. D. Jap, “The Dark Side of Close Relationships The Dark Side of Close Relationships,” vol. 46, no. 3, 2005.

[2] Y. Baba, N. Shichijo, and S. R. Sedita, "How do collaborations with universities affect firms' innovative performance? The role of 'Pasteur scientists' in the advanced materials field,” vol. 38, no. 5, pp. 756-764.

[3] C. Beaudry and A. Schiffauerova, "Impacts of collaboration and network indicators on patent quality: The case of Canadian nanotechnology innovation," vol. 29, no. 5, pp. 362-376.

[4] L. M. Camarinha-Matos and H. Afsarmanesh, “Collaborative Networks,” pp. 2640 .

[5] M. Cuijpers, H. Guenter, and K. Hussinger, "Costs and benefits of interdepartmental innovation collaboration,” vol. 40, no. 4, pp. 565-575.

[6] C. Huxham and D. Macdonald, "Introducing Collaborative Advantage: Achieving Inter

[7] M. Kloyer and J. Scholderer, "Effective incomplete contracts and milestones in market-distant R\&D collaboration,” vol. 41, no. 2, pp. 346-357.

[8] B. Lokshin, J. Hagedoorn, and W. Letterie, “The bumpy road of technology partnerships: Understanding causes and consequences of partnership malfunctioning,” vol. 40, no. 2, pp. 297-308.

[9] J. Mata and M. Woerter, "Risky innovation: The impact of internal and external R\&D strategies upon the distribution of returns,” vol. 42, no. 2, pp. 495-501.

[10] B. Patrakosol and D. L. Olson, "How interfirm collaboration benefits $\{$ IT $\}$ innovation,” vol. 44, no. 1, pp. 53-62.

[11] R. Petzel, A.-M. Archer, and R. Fei, “Collaboration for sustainability in a networked world,” vol. 2, no. 4, pp. 6597-6609.

[12] S. Roper, J. Du, and J. H. Love, "Modelling the innovation value chain,” vol. 37, no. 6, pp. 961-977.

[13] G. Vickery, "Networks in the Knowledge Economy Restructuring Value Chains," pp. 221-240.

[14] D. S. Yim and B.-S. Kang, "Policy options for establishing effective subnational innovation systems and technological capacity-building,” vol. 4, pp. 115-137. 
[15] R. Zeidner, L., and Woods, "The Collaborative Innovation (CI) Process,” Altshuller Inst., 2000.

[16] T. Bucic, S. P. Gudergan, and others, "The innovation process in alliances," in The Third European Conference on Organizational Knowledge, Learning and Capabilities, Athens, Greece, 2002, pp. 5-6. 